\title{
Economic Evaluation of Global Endometrial Ablation Versus Inpatient and Outpatient Hysterectomy for Treatment of Abnormal Uterine Bleeding: US Commercial and Medicaid Payer Perspectives
}

\author{
Jeffrey D. Miller, MS,, Machaon M. Bonafede, PhD, MPH, Qian Cai, MS, MSPH, Scott K. Pohlman, MS, \\ Kathleen A. Troeger, $\mathrm{MPH}^{2}$, and Aarathi Cholkeri-Singh, $\mathrm{MD}^{3}$
}

\begin{abstract}
Every year, abnormal uterine bleeding (AUB) exacts a heavy toll on women's health and leads to high costs for the US health care system. The literature shows that endometrial ablation results in fewer complications, shorter recovery and lower costs than more commonly performed hysterectomy procedures. The objective of this study was to model clinical-economic outcomes, budget impact, and cost-effectiveness of global endometrial ablation (GEA) versus outpatient hysterectomy (OPH) and inpatient hysterectomy (IPH) procedures. A decision tree, state-transition (semi-Markov) economic model was developed to simulate 3 hypothetical cohorts of women who received surgical treatment for AUB (GEA, OPH, and IPH) over 1, 2, and 3 years to evaluate clinical and economic outcomes for GEA vs. OPH and GEA vs. IPH. Two versions of the model were created to reflect both commercial health care payer and US Medicaid perspectives, and analyses were conducted for both payer types. Total health care costs in the first year after GEA were substantially lower compared with those for IPH and OPH. Budget impact analysis results showed that increasing GEA utilization yields total annual cost savings of about $\$ 906,000$ for a million-member commercial health plan and about $\$ 152,000$ in cost savings for a typical-sized state Medicaid plan with 1.4 million members. Cost-effectiveness analysis results for both perspectives showed GEA as economically dominant (conferring greater benefit at lower cost) over both OPH and IPH in the 1-year commercial scenario. This study demonstrates that, for some patients, GEA may prove to be a safe, uterus-sparing, cost-effective alternative to OPH and IPH for the surgical treatment of AUB.
\end{abstract}

Keywords: global endometrial ablation, abnormal uterine bleeding, economic evaluation

\section{Introduction}

C HaRacterized By heavy, prolonged, or excessive menstrual flow, abnormal uterine bleeding (AUB) is known to interfere with a woman's physical, social, and/or material quality of life. ${ }^{1-8}$ In the United States, the prevalence of AUB ranges from $10 \%$ to $30 \%$ among women of reproductive age, affecting more than 10 million women each year. ${ }^{8-11}$ Moreover, nearly one third of all office visits to gynecologists are related to AUB, $, 7,12$ generating annual estimated direct costs of $\$ 1-\$ 1.55$ billion and indirect costs of $\$ 12-\$ 36$ billion. $^{11}$
Although hysterectomy remains the most common surgical treatment for AUB, it is associated with significant morbidity, a lengthy recovery period, rare instances of mortality, and high health care costs. ${ }^{6,8,13}$ Endometrial ablation offers a minimally invasive alternative that preserves the uterus with fewer adverse effects, a shorter recovery period and lower costs. Non-resectoscopic global endometrial ablation (GEA) is a second-generation technique that can be performed without general anesthesia in an outpatient setting. ${ }^{3,6,7,14}$ Because the uterus is left intact, there is a risk for reintervention; in fact, rates of subsequent hysterectomy range from $2.5 \%$ to $21 \%$ over a 5 -year period.

\footnotetext{
${ }^{1}$ Truven Health Analytics, an IBM Company, Cambridge, Massachusetts.

${ }^{2}$ Hologic, Inc., Marlborough, Massachusetts.

${ }^{3}$ The Advanced Gynecologic Surgery Institute, Naperville, Illinois.
} 
GEA procedures are becoming more common and, with the steady shift toward seeking higher value, safer, more effective treatments that reduce the overall cost of care, GEA represents an increasingly appealing alternative to inpatient procedures. Previous AUB economic evaluation models ${ }^{23,24}$ did not consider outpatient and inpatient hysterectomy separately. The study described herein evaluated the clinicaleconomic outcomes, budget impact, and cost-effectiveness of AUB treatment with GEA versus outpatient hysterectomy $(\mathrm{OPH})$ and inpatient hysterectomy (IPH) from both US commercial and Medicaid payer perspectives.

\section{Methods}

\section{Model structure and target population}

A decision tree, state-transition (semi-Markov) economic model was developed in Microsoft Excel 2016 (Microsoft Corporation, Redmond, WA) to simulate 3 hypothetical patient cohorts of women receiving a surgical treatment intervention for AUB. The first cohort was treated with GEA, the second was treated with $\mathrm{OPH}$, and the third was treated with IPH (Fig. 1). The GEA cohort encompassed the blend of uterine ablation modalities currently utilized in US real-world treatment settings including bipolar radiofrequency ablation and all other second-generation GEA techniques (eg, cryotherapy, microwave endometrial ablation, thermal balloon endometrial ablation, hydrothermal ablation). Similarly, the $\mathrm{OPH}$ and IPH cohorts represented composites of real-world utilization of laparoscopic/robotic-assisted hysterectomy, vaginal hysterectomy, and abdominal hysterectomy.

The cohorts were simulated in the model over 1-, 2-, and 3 -year horizons in yearly iterations or "cycles" to evaluate clinical and economic outcomes for GEA vs. OPH and GEA vs. IPH. For informational purposes, benchmarking comparisons were made for OPH vs. IPH as well. The modeling methods and overall evaluation approach used to develop this model and for conducting analyses using the model are consistent with other economic models and evaluations of AUB treatment with GEA and hysterectomy that have been developed in recent years, ${ }^{25-27}$ as well as previously published versions of the updated model ${ }^{23,24}$ utilized for this study. Updates include recent data and the added ability to differentiate comparisons between OPH and IPH.

Two versions of the model were created: one based on clinical and economic data oriented toward the US commercial health care payer perspective and the other oriented toward a US Medicaid perspective. Although the underlying clinical and cost data for the 2 models differ, the structure and functional operation of the models are identical. Comparisons made among these 2 payer types in the previously published model ${ }^{23,24}$ showed meaningful differences, not only because of fundamental differences in reimbursement tendered by commercial payers in contrast with Medicaid, but also because of the inherent differences in the patient populations. Patients tend to vary with regard to demographics, economic status, health status, treatment-seeking behaviors, and the types and quality of clinicians and health care institutions providing for their medical needs.

The focus of the present modeling analyses was on the stratum of premenopausal women aged 30-55 years for whom childbearing is complete and who seek a permanent, nonreversible, 1-time treatment option for their AUB with either GEA or hysterectomy. The sociodemographic profiles of the cohorts reflect real-world, observational data from insurance claims database analyses specially conducted for this study. As shown in Figure 1, simulations begin at the point where AUB treatment with GEA, OPH, or IPH is initiated. In any given model cycle, the patient cohorts either remain in or move between discrete health states to replicate the natural course of postintervention AUB treatment over time.

Initial intervention for all 3 treatments is modeled with and without probability of complications, and GEA is further modeled with and without probability of secondary reintervention (which bears risk for associated complication). GEA patients are assumed to recover to a well health state within 1 month of the intervention. OPH and IPH patients are assumed to have a 3-month convalescence.

In the first year, GEA reinterventions are modeled to occur 6 months following the initial intervention (exactly replicating the interval observed in the underlying claims database analyses) and assumed to likewise occur at the 6month point in the second and third years of simulation. Time-varying transition probabilities, costs, and quality-oflife (ie, "utility") values are ascribed to each health state and vary according to the characteristics of the particular treatment options being compared.

At the end of each simulation $(1,2$, or 3 years), differences in cumulative total costs and outcomes between treatment cohorts generate estimates of total and incremental differences in costs and quality-adjusted life years (QALYs). These, in turn, are used to generate estimates of the budget impact and cost-effectiveness of GEA as an AUB intervention.

\section{Data inputs and sources}

Database analyses. All clinical and economic data for the model (including treatment patterns, health state transition probabilities, health care resource utilization, and costs) were derived from de novo analyses of 2 large medical claims databases: (1) the Truven Health MarketScan ${ }^{\circledR}$ Commercial Claims and Encounters Database, and (2) the Truven Health MarketScan ${ }^{\circledR}$ Medicaid Multi-State Database. The analyses were a regeneration of the analyses that informed the previous version of the model. ${ }^{23,24}$ These databases provide clinical and cost information on individuals covered by a variety of employer-sponsored private health insurance plans and employer-paid Medicare supplemental insurance and are considered nationally representative of persons with employer-sponsored health insurance with respect to geography, age, and sex.

The database analyses conducted for informing this modeling study featured female patients aged 30-55 years with AUB who had GEA, OPH, or IPH during the time period spanning January 1, 2013, to June 30, 2015. Patients were required to have $\geq 12$ months of continuous enrollment with medical and pharmacy benefits in the database before intervention and $\geq 12$ months of continuous enrollment with medical and pharmacy benefits after the intervention. Patients were excluded if in the 12-month preintervention period they were menopausal or had claims for GEA or hysterectomy. Patients also were excluded if they had claims for pregnancy or birth in the 12-month 


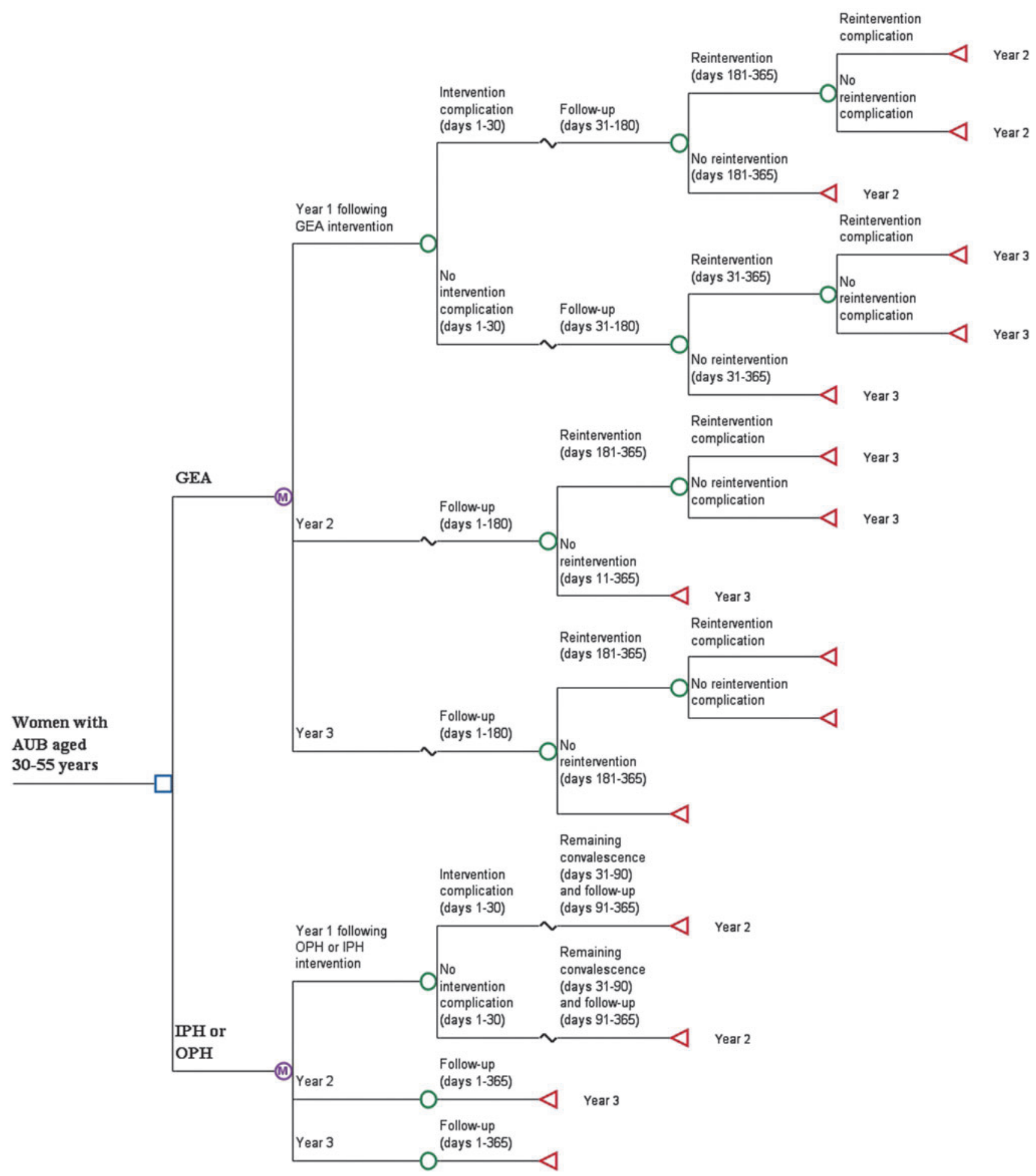

FIG. 1. Decision tree diagram of the economic model. AUB, abnormal uterine bleeding; GEA, global endometrial ablation; IPH, inpatient hysterectomy; OPH, outpatient hysterectomy.

preintervention or 12-month postintervention period. Also, patients with primary cancer (except skin cancer) in the 12-month preintervention or 12-month postintervention period were excluded.

$\mathrm{OPH}$ and IPH were defined by the specific setting in which hysterectomies were performed (ie, "outpatient" vs. "inpa- tient" treatment setting), as integrally flagged in the claims data. Generally, IPH requires a hospital admission whereas $\mathrm{OPH}$ can occur in a hospital if the patient is not formally admitted. After applying inclusion/exclusion criteria, the commercial payer analyses were conducted on a final data set of 31,629 GEA patients, 14,548 OPH patients, and 10,488 IPH 
Initial intervention cost (year 1, days 1-30)

\begin{tabular}{lrr}
\hline Intervention & $\begin{array}{c}\text { Commercial payer } \\
\text { perspective }\end{array}$ & $\begin{array}{c}\text { Medicaid payer } \\
\text { perspective }\end{array}$ \\
\hline GEA & $\$ 3426.35$ & $\$ 765.83$ \\
OPH & $\$ 6841.88$ & $\$ 1106.68$ \\
IPH & $\$ 10,046.68$ & $\$ 2822.25$ \\
\hline
\end{tabular}

All other health care costs (year 1, days 1-365) for patients with and without complications* and stratified by reintervention status for GEA patients

Intervention and patient type

Commercial payer perspective

$\$ 9646.61$

$\$ 8187.62$

$\$ 22,240.19$

$\$ 7187.31$

Without reintervention

Patients without complications from initial intervention

Day $1-30$

Days 31-365

With reintervention

Without reintervention

OPH

Patients with complications from initial intervention

Day $1-30$

Days 31-365

Patients without complications from initial intervention

Day $1-30$

Days 31-365

IPH

Patients with complications from initial intervention

Day 1-30

Days 31-365

$\$ 7511.49$

$\$ 7075.35$

$\$ 23,955.32$

$\$ 6254.40$

$\$ 16,380.03$

$\$ 6223.04$

$\$ 15,753.73$

$\$ 6582.56$

$\$ 17,688.32$

$\$ 7055.48$

$\$ 17,264.72$

$\$ 7485.89$

Patients without complications from initial intervention

Day 1-30

Days 31-365
Medicaid payer perspective
$\$ 3767.62$

$\$ 7881.96$

$\$ 12,293.62$

$\$ 7593.76$

$\$ 3447.77$

$\$ 9497.99$

$\$ 14,927.22$

$\$ 9053.89$

$\$ 5314.97$

$\$ 7478.80$

$\$ 4967.46$

$\$ 8797.65$

$\$ 5635.69$

$\$ 8482.81$

$\$ 5529.40$

$\$ 8876.68$

All other health care costs (year 2, days 1-365), stratified by reintervention status for GEA patients

\begin{tabular}{lcc}
\hline Intervention and patient type & $\begin{array}{c}\text { Commercial payer } \\
\text { perspective }\end{array}$ & $\begin{array}{c}\text { Medicaid payer } \\
\text { perspective }\end{array}$ \\
\hline GEA & $\$ 8617.10$ & $\$ 11,573.17$ \\
With reintervention & $\$ 25,240.15$ & $\$ 12,537.98$ \\
Without reintervention & $\$ 7994.83$ & $\$ 11,523.91$ \\
OPH & $\$ 8031.11$ & $\$ 11,004.18$ \\
IPH & $\$ 8879.28$ & $\$ 9973.14$ \\
\hline
\end{tabular}

All other health care costs (year 3, days 1-365), stratified by reintervention status for GEA patients

\begin{tabular}{lcc}
\hline Intervention and patient type & $\begin{array}{c}\text { Commercial payer } \\
\text { perspective }\end{array}$ & $\begin{array}{c}\text { Medicaid payer } \\
\text { perspective }\end{array}$ \\
\hline GEA & $\$ 9869.85$ & $\$ 14,170.58$ \\
With reintervention & $\$ 29,221.38$ & $\$ 22,693.39$ \\
Without reintervention & $\$ 9240.62$ & $\$ 13,764.74$ \\
OPH & $\$ 8875.06$ & $\$ 11,269.79$ \\
IPH & $\$ 9837.38$ & $\$ 11,341.82$ \\
\hline
\end{tabular}

All data derived from MarketScan database analyses, with costs adjusted to 2017 US dollars.

*Complications: cervical occlusion, cervical trauma (including cervical lacerations and hematometra), cervical/uterine/bowel perforation, fluid overload, pyometra, cervicitis and device complications.

GEA, global endometrial ablation; IPH, inpatient hysterectomy; OPH, outpatient hysterectomy. 
patients, while the Medicaid analyses were conducted on a final data set of 4140 GEA patients, $2170 \mathrm{OPH}$ patients, and 1288 IPH patients.

Model input parameters. Costs of intervention, intervention complications, and reintervention (for GEA patients), along with all other health care costs incurred by women in the analysis data sets were evaluated for up to 3 years of follow-up time, and resulting estimates of mean costs (disaggregated by year of occurrence and by complication and reintervention status) and probabilities of complication and reintervention were converted into model input parameters (Tables 1-2)

Interventions and reinterventions. As already mentioned, intervention with GEA in the model was represented by the blend of second-generation GEA techniques used by the 31,629 and 4140 women who had GEA as an AUB intervention in the commercial and Medicaid database analyses, respectively. Similarly, OPH and IPH comprised the blend of real-world hysterectomy techniques for the women who had hysterectomy in the database analyses.

In each of the 3 years following GEA intervention, women in the database analyses were observed to have a small but not insignificant chance of reintervention (with possibility of their own reintervention complications), either with a secondary GEA, or with OPH or IPH. Reintervention events were parameterized into the model, summarized in Table 2, as 3 sets of reintervention probabilities and reintervention-type distributions pertaining to the 3 sequential years after initial GEA intervention.

Intervention/reintervention complications. Probabilities of intervention complications in the first month (30 days) following intervention or reintervention are listed in Table 2. Complications included cervical occlusion, cervical trauma (including cervical lacerations and hematometra), cervical/ uterine/bowel perforation, fluid overload, pyometra, cervicitis and device complications. Longer term (>30 days) complications following hysterectomy, such as pelvic organ prolapse, which has a high incidence of 1.3 per 1000 women-years, ${ }^{28}$ were not classified as "complications," although their associated costs were fully accounted for in the model calculations. As already described, all complications probabilities were derived from the MarketScan database analyses.

Costs. As economic inputs to the model, costs of intervention and associated 30-day follow-up costs attributable to the intervention for GEA, OPH, and IPH are shown in Table 1. All other health care costs for patients with and without complications in the first 30 days following intervention and in the remainder of the first year and in the subsequent 2 years also are shown in Table 1 .

These costs are actual payments to health care providers from adjudicated insurance claims, and are not billed charges. They represent true "all health care expenditure" incurred by patients and are not limited to only their AUB intervention or utilization of gynecological-related health care. Costs for GEA patients are further disaggregated by reintervention status. As already described, all cost estimates were derived from the MarketScan database analyses and adjusted to 2017 US dollars using the Medical Care component of the US Consumer Price Index.
Table 2. Model Transition Probabilities AND DISTRIBUTIONS

Probability of complication* (year 1, days 1-30, and applicable to all subsequent reinterventions for GEA patients)

\begin{tabular}{lcc}
\hline Intervention & $\begin{array}{c}\text { Commercial } \\
\text { payer } \\
\text { perspective }\end{array}$ & $\begin{array}{c}\text { Medicaid } \\
\text { payer }\end{array}$ \\
\hline perspective
\end{tabular}

Probability of reintervention for GEA patients

\begin{tabular}{lcc}
\hline & $\begin{array}{c}\text { Commercial } \\
\text { payer } \\
\text { Reintervention year }\end{array}$ & $\begin{array}{c}\text { Medicaid } \\
\text { payer } \\
\text { perspective }\end{array}$ \\
\hline Year 1 & 0.0491 & 0.0775 \\
$\quad \begin{array}{l}\text { Patients with initial GEA } \\
\quad \text { intervention complications* }\end{array}$ & 0.0692 & 0.0635 \\
$\quad \begin{array}{l}\text { Patients without initial GEA } \\
\quad \text { intervention complications* }\end{array}$ & 0.0483 & 0.0783 \\
Year 2 & 0.0372 & 0.0502 \\
Year 3 & 0.0321 & 0.0455
\end{tabular}

Distribution of type of reintervention for GEA patients

\begin{tabular}{lrr}
$\begin{array}{l}\text { Reintervention } \\
\text { type by year }\end{array}$ & $\begin{array}{c}\text { Commercial } \\
\text { payer } \\
\text { perspective }\end{array}$ & $\begin{array}{c}\text { Medicaid } \\
\text { payer } \\
\text { perspective }\end{array}$ \\
\hline Year 1 & & \\
$\quad$ Secondary GEA as & $9.0 \%$ & $7.5 \%$ \\
$\quad$ reintervention & $75.9 \%$ & $82.6 \%$ \\
OPH as reintervention & $15.1 \%$ & $10.0 \%$ \\
IPH as reintervention & $100.0 \%$ & $100.0 \%$ \\
& & \\
Year 2 & $6.3 \%$ & $8.8 \%$ \\
Secondary GEA as & & \\
$\quad$ reintervention & $82.9 \%$ & $83.5 \%$ \\
OPH as reintervention & $10.9 \%$ & $7.7 \%$ \\
IPH as reintervention & $100.0 \%$ & $100.0 \%$ \\
$\quad$ & \\
Year 3 & $4.9 \%$ & $7.7 \%$ \\
Secondary GEA as & & \\
$\quad$ reintervention & $87.1 \%$ & $84.6 \%$ \\
OPH as reintervention & $8.0 \%$ & $7.7 \%$ \\
IPH as reintervention & $100.0 \%$ & $100.0 \%$ \\
&
\end{tabular}

All data derived from MarketScan database analyses.

*Complications: cervical occlusion, cervical trauma (including cervical lacerations and hematometra), cervical/uterine/bowel perforation, fluid overload, pyometra, cervicitis and device complications.

GEA, global endometrial ablation; IPH, inpatient hysterectomy; $\mathrm{OPH}$, outpatient hysterectomy.

Health state utility values. Health state utilities used in the model calculations are shown in Table 3. In general, utilities can vary between $0=$ death and $1=$ perfect health and are used to calculate QALYs, a fundamental part of cost-effectiveness calculations. Utility data in Table 3 were derived from other patientreported outcomes studies with quality-of-life assessments for endometrial ablation and hysterectomy, 26,27,29,30 mostly originating from the studies by Sculpher et $\mathrm{al}^{31}$ and Hurskainen et al. ${ }^{32}$ 
Table 3. Model Utility Parameters (Both Commercial Payer and Medicaid Payer Perspectives)

\begin{tabular}{|c|c|c|}
\hline Intervention and outcome scenario & Utility & Source \\
\hline \multicolumn{3}{|c|}{ Intervention/Reintervention without Complications* } \\
\hline GEA (Month 1, “Well”' after) & 0.76 & Roberts et $\mathrm{al}^{27}$ and Bhattacharya et $\mathrm{al}^{26}$ \\
\hline OPH (Month 1) & 0.56 & $\begin{array}{l}\text { Roberts et } \mathrm{al}^{21} \text { and Bhattacharya et al, }{ }^{26} \text { as adapted from } \\
\text { Sculpher et } \mathrm{al}^{31}\end{array}$ \\
\hline OPH (Months 2-3, “Well” after) & 0.74 & $\begin{array}{l}\text { Roberts et } \mathrm{al}^{27} \text { and Bhattacharya et al, }{ }^{26} \text { as adapted from } \\
\text { Sculpher et } \mathrm{al}^{31}\end{array}$ \\
\hline IPH (Month 1) & 0.56 & Assumed to be the same as OPH \\
\hline IPH (Months 2-3, “Well” after) & 0.74 & Assumed to be the same as OPH \\
\hline \multicolumn{3}{|c|}{ Intervention/Reintervention with Complications* } \\
\hline GEA (Month 1, “Well” after) & 0.50 & $\begin{array}{l}\text { Assumed to be the average (rounded to } 2 \text { decimal places) of } \\
\text { "severe complications post second-generation EA" } \\
\text { (ie, } 0.49 \text {, as derived from Clegg et } \mathrm{al}^{29} \text { ) and "symptomatic } \\
\text { post second-generation EA" (ie, } 0.50 \text {, as derived from the } \\
\text { utility value of "menorrhagia" presented by Sculpher et } \mathrm{al}^{31} \text { ) } \\
\text { as presented in the economic models developed by Roberts } \\
\text { et } \mathrm{al}^{27} \text { and Bhattacharya et } \mathrm{al}^{26}\end{array}$ \\
\hline OPH (Month 1) & 0.49 & $\begin{array}{l}\text { Roberts et } \mathrm{al}^{27} \text { and Bhattacharya et } \mathrm{al}^{26} \text { as derived from } \\
\text { Clegg et } \mathrm{al}^{29} \text { and Garside et } \mathrm{al}^{30}\end{array}$ \\
\hline OPH (Months 2-3, “Well” after) & 0.49 & $\begin{array}{l}\text { Assumed to be the same as hysterectomy with complications } \\
\text { in Month } 1 .\end{array}$ \\
\hline IPH (Month 1) & 0.49 & Assumed to be the same as OPH \\
\hline IPH (Months 2-3, “Well”, after) & 0.49 & Assumed to be the same as OPH \\
\hline \multicolumn{3}{|l|}{ Well } \\
\hline GEA (Post-Convalescence) & 0.84 & $\begin{array}{l}\text { Assumed the same as "well post second-generation EA," per } \\
\text { Roberts et } \mathrm{al}^{27} \text { and Bhattacharya et al, }{ }^{26} \text { as derived from } \\
\text { Hurskainen et } \mathrm{al}^{32}\end{array}$ \\
\hline OPH (Post-Convalescence) & 0.88 & $\begin{array}{l}\text { Assumed same as "well post hysterectomy," per Roberts et } \mathrm{al}^{27} \\
\text { and Bhattacharya et al, }{ }^{26} \text { as derived from Hurskainen et al }\end{array}$ \\
\hline IPH (Post-Convalescence) & 0.88 & Assumed to be the same as $\mathrm{OPH}$ \\
\hline
\end{tabular}

*Complications: cervical occlusion, cervical trauma (including cervical lacerations and hematometra), cervical/uterine/bowel perforation, fluid overload, pyometra, cervicitis and device complications.

EA, endometrial ablation; GEA, global endometrial ablation; IPH, inpatient hysterectomy; OPH, outpatient hysterectomy.

\section{Model analysis outcomes}

Costs and QALYs analysis. Analytical results generated by the model include an assortment of comparative economic outcomes, including total and incremental costs and QALYs, budget impact, and incremental cost-utility ratios (ICURs). Specifically, model analysis outcomes include total health care costs and their incremental $(\%)$ differences for Years 1, 2, and 3 and cumulative for Years 1-2 and Years 1-3.

Disaggregation of costs by their locus of utilization are reported for the Year 1 analyses (ie, costs attributable to intervention, inpatient hospitalizations, outpatient visits and services, pharmacy purchases). Similarly, model analysis outcomes also include total and incremental QALYs, with percentage differences for Years 1, 2, and 3 and cumulative for Years 1-2 and Years 1-3. An annual discount rate of 3\% was applied to the cumulative costs and QALYs in the analyses extending beyond 1 year.

Budget impact analysis. Results of the cost analyses are subsequently used as the inputs for payer-perspective budget impact analyses that evaluate the financial impact on a hypothetical US health plan or state Medicaid plan 1 year after preferably increasing AUB treatment utilization with GEA instead of OPH and IPH. Cohorts of AUB patients are run alternatively through 2 analytical scenarios: (1) Current Scenario, featuring the existing level of GEA utilization by the health plan or Medicaid plan, and (2) Revised Scenario, where there is a hypothetical increase in utilization of GEA, taking share of utilization from OPH and IPH.

While the Current Scenario is grounded in real-world utilization data derived from the MarketScan database analyses, the modeled changes in utilization of the oral anticoagulant therapies are hypothetical but meant to realistically test what would happen if a health plan or Medicaid plan were to alter the mix of AUB treatment modalities utilized by their covered patients. In the analyses presented here, utilization of GEA in the Revised Scenario is assumed to increase by $20 \%$ with a corresponding decrease in utilization of OPH and IPH by $15 \%$ and $5 \%$, respectively.

Within these 2 scenarios (ie, Current, Revised), economic outcomes are simulated for 1 year and compared against each other, with the difference in costs between the 2 scenarios being the net budget impact of the shift toward greater utilization of GEA. In addition to total and incremental costs to the health plan or Medicaid, results are expressed as per-member per-month (PMPM) and per-treatedmember per-month (PTMPM) cost (or cost savings), which are budget impact analysis metrics commonly used by health care decision makers.

The commercial payer budget impact analysis is based on a hypothetical 1 million member health plan, which would be expected to comprise $16.3 \%(163,000)$ women aged 30-55 years (based on 2016 US Census Bureau population 
estimates). Within this population, an AUB prevalence of about $20 \%(32,600)$ would be expected, based on commonlycited AUB prevalence statistics that range from $10 \%$ to $30 \% .^{8-11}$ From the MarketScan database analyses, an estimated $1.1 \%$ of AUB patients receive GEA or hysterectomy intervention in any given year. Applying the drilldown of these statistics, the commercial payer budget impact analysis focused on the resulting 362 AUB patients in a hypothetical million-member health plan who would receive GEA or hysterectomy intervention in any given year.

The Medicaid budget impact analysis is based on an average state Medicaid plan size of 1.4 million enrollees. ${ }^{33}$ Applying the same statistics used for the commercial payer budget impact analysis, the Medicaid budget impact analysis focused on 507 Medicaid AUB patients who would receive GEA or hysterectomy intervention in any given year.

Cost-effectiveness analysis. The cost analyses results generated by the model also are used to calculate the ICURs, which are the ratio of the incremental difference in costs and the incremental difference in QALYs (ie, Costs ${ }_{\mathrm{GEA}}$ - Costs OPHor- $_{\text {OPH }}$ $\left.{ }_{\mathrm{IPH}} / \mathrm{QALY} \mathrm{s}_{\mathrm{GEA}}-\mathrm{QALY}_{\mathrm{OPHorIPH}}\right)$. ICURs can be used to subjectively evaluate the relative cost-effectiveness of GEA vs. OPH and GEA vs. IPH from a US health plan or Medicaid perspective. An annual discount rate of $3 \%$ was applied to the ICURs in the analyses extending beyond 1 year.

Analyses comparing OPH vs. IPH. For benchmarking and general information purposes, the scope of the model outputs includes total and incremental comparisons of $\mathrm{OPH}$ vs. IPH, as well as the comparative cost-effectiveness of the 2 hysterectomy modalities. Although not the main focus of this study, results of these comparisons are incidentally shown in the tables presented here.

Sensitivity analyses. Targeted sensitivity analyses were conducted to test the robustness of GEA model parameter values and their impact on model results, including budget impact and cost-effectiveness of GEA. GEA complication rate and reintervention rate parameters were varied by $+/$ $25 \%$, and GEA utility values were varied by $+/-10 \%$. To test the sensitivity of the model to variations in cost, median values for all cost parameters derived from the MarketScan database analyses were substituted for the mean cost values programmed in the model; this was performed simultaneously for all 3 interventions. Probabilistic sensitivity analyses were not conducted in the present version of the model.

\section{Results}

\section{Costs and QALYs analysis}

Commercial payer perspective. In the commercial payer perspective analysis, total health care costs in the first year after intervention (including costs for the initial procedure, complications, and any necessary reinterventions) for AUB patients treated with GEA were $\$ 18,141$, compared with $\$ 29,266$ for OPH and $\$ 34,795$ for IPH, thus showing an incremental cost savings for GEA ranging from $\$ 11,125(-61.3 \%)$ to $\$ 16,654(-91.8 \%)$ (Table 4 and Fig. 2). Looking at intervention costs alone, GEA saved

Table 4. Cost and Quality-Adjusted Life Year Outcomes (Commercial Payer Perspective)

\begin{tabular}{|c|c|c|c|c|c|c|c|c|c|}
\hline & $G E A$ & $O P H$ & $I P H$ & $\begin{array}{c}\triangle G E A v s . \\
O P H\end{array}$ & $\begin{array}{l}\triangle G E A \\
\text { vs. IPH }\end{array}$ & $\begin{array}{l}\triangle O P H \\
\text { vs } I P H\end{array}$ & $\begin{array}{l}\% \triangle G E A \\
\text { vs. } O P H\end{array}$ & $\begin{array}{c}\% \Delta G E A \\
v s . I P H\end{array}$ & $\begin{array}{c}\% \triangle O P H \\
\text { vs } I P H\end{array}$ \\
\hline Year 1 Total Cost & $\$ 18,141$ & $\$ 29,266$ & $\$ 34,795$ & $-\$ 11,125$ & $-\$ 16,654$ & $-\$ 5529$ & $-61.3 \%$ & $-91.8 \%$ & $-18.9 \%$ \\
\hline Initial intervention & $\$ 3426$ & $\$ 6842$ & $\$ 10,047$ & $-\$ 3416$ & $-\$ 6620$ & $-\$ 3205$ & $-99.7 \%$ & $-193.2 \%$ & $-46.8 \%$ \\
\hline $\begin{array}{l}\text { All other health care } \\
\quad \text { (including reintervention) }\end{array}$ & $\$ 14,715$ & $\$ 22,425$ & $\$ 24,749$ & $-\$ 7709$ & $-\$ 10,033$ & $-\$ 2324$ & $-52.4 \%$ & $-68.2 \%$ & $-10.4 \%$ \\
\hline Inpatient admissions & $\$ 1218$ & $\$ 1243$ & $\$ 7124$ & $-\$ 25$ & $-\$ 5906$ & $-\$ 5881$ & $-2.1 \%$ & $-484.9 \%$ & $-473.1 \%$ \\
\hline Outpatient services & $\$ 11,893$ & $\$ 19,586$ & $\$ 15,920$ & $-\$ 7693$ & $-\$ 4027$ & $\$ 3667$ & $-64.7 \%$ & $-33.9 \%$ & $18.7 \%$ \\
\hline Emergency room visits & $\$ 616$ & $\$ 846$ & $\$ 973$ & $-\$ 230$ & $-\$ 357$ & $-\$ 127$ & $-37.3 \%$ & $-57.9 \%$ & $-15.0 \%$ \\
\hline Physician office visits & $\$ 511$ & $\$ 511$ & $\$ 550$ & $\$ 1$ & $-\$ 38$ & $-\$ 39$ & $0.2 \%$ & $-7.5 \%$ & $-7.7 \%$ \\
\hline Other outpatient services & $\$ 10,766$ & $\$ 18,230$ & $\$ 14,397$ & $-\$ 7464$ & $-\$ 3632$ & $\$ 3832$ & $-69.3 \%$ & $-33.7 \%$ & $21.0 \%$ \\
\hline Outpatient prescriptions & $\$ 1604$ & $\$ 1595$ & $\$ 1705$ & $\$ 9$ & $-\$ 101$ & $-\$ 109$ & $0.5 \%$ & $-6.3 \%$ & $-6.9 \%$ \\
\hline Year 2 Total Cost & $\$ 8617$ & $\$ 8031$ & $\$ 8879$ & $\$ 586$ & $-\$ 262$ & $-\$ 848$ & $6.8 \%$ & $-3.0 \%$ & $-10.6 \%$ \\
\hline Year 3 Total Cost & $\$ 9870$ & $\$ 8875$ & $\$ 9837$ & $\$ 995$ & $\$ 32$ & $-\$ 962$ & $10.1 \%$ & $0.3 \%$ & $-10.8 \%$ \\
\hline $\begin{array}{l}\text { Cumulative Total Cost } \\
\text { (Years 1-2) (Discounted } \\
\text { at 3\%) }\end{array}$ & $\$ 25,979$ & $\$ 36,211$ & $\$ 42,402$ & $-\$ 10,232$ & $-\$ 16,423$ & $-\$ 6191$ & $-39.4 \%$ & $-63.2 \%$ & $-17.1 \%$ \\
\hline $\begin{array}{l}\text { Cumulative Total Cost } \\
\text { (Years 1-3) (Discounted } \\
\text { at 3\%) }\end{array}$ & $\$ 34,526$ & $\$ 43,522$ & $\$ 50,440$ & $-\$ 8996$ & $-\$ 15,914$ & $-\$ 6918$ & $-26.1 \%$ & $-46.1 \%$ & $-15.9 \%$ \\
\hline Year 1 QALYs & 0.8304 & 0.8143 & 0.8156 & 0.0162 & 0.0149 & -0.0013 & $1.9 \%$ & $1.8 \%$ & $-0.2 \%$ \\
\hline Year 2 QALYs & 0.8403 & 0.8800 & 0.8800 & -0.0397 & -0.0397 & 0.0000 & $-4.7 \%$ & $-4.7 \%$ & $0.0 \%$ \\
\hline Year 3 QALYs & 0.8419 & 0.8800 & 0.8800 & -0.0381 & -0.0381 & 0.0000 & $-4.5 \%$ & $-4.5 \%$ & $0.0 \%$ \\
\hline $\begin{array}{l}\text { Cumulative QALYs (Years 1-2) } \\
\text { (Discounted at 3\%)) }\end{array}$ & 1.6220 & 1.6449 & 1.6462 & -0.0229 & -0.0241 & -0.0013 & $-1.4 \%$ & $-1.5 \%$ & $-0.1 \%$ \\
\hline $\begin{array}{l}\text { Cumulative QALYs (Years 1-3) } \\
\text { (Discounted at 3\%)) }\end{array}$ & 2.3684 & 2.4265 & 2.4277 & -0.0581 & -0.0594 & -0.0012 & $-2.5 \%$ & $-2.5 \%$ & $-0.1 \%$ \\
\hline
\end{tabular}

All costs are in 2017 US dollars.

GEA, global endometrial ablation; IPH, inpatient hysterectomy; OPH, outpatient hysterectomy; QALY, quality-adjusted life year. 


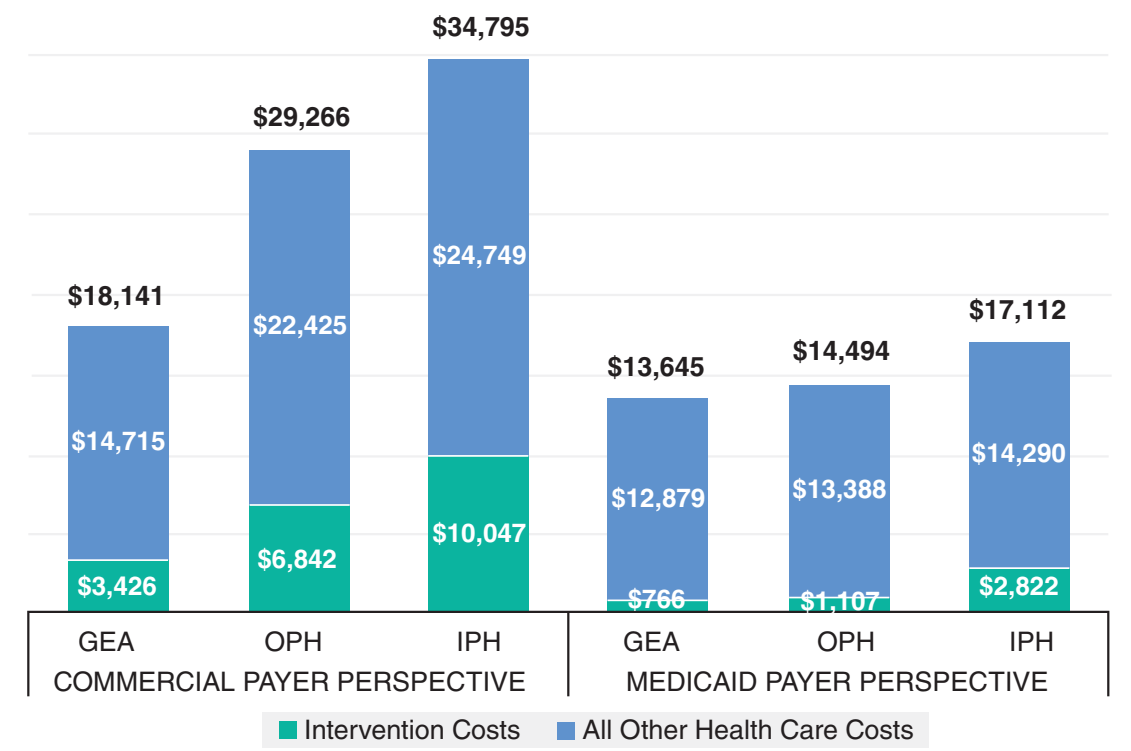

FIG. 2. One-year health care costs following AUB intervention. AUB, abnormal uterine bleeding; GEA, global endometrial ablation; IPH, inpatient hysterectomy; OPH, outpatient hysterectomy.

$\$ 3416$ vs. OPH and $\$ 6620$ vs. IPH. Other disaggregated 1-year comparisons for inpatient, outpatient, and pharmacy costs are presented in Table 4.

Second and third year postintervention costs were lower than the initial year (ranging from about $\$ 8000$ to $\$ 10,000$ across all 3 interventions), with GEA costs somewhat higher $(6.8 \%-10.1 \%)$ than OPH costs and slightly lower than IPH costs in the second year $(-0.3 \%)$ and higher than IPH costs in the third year $(+3.0 \%)$. However, discounted cumulative costs across 2- and 3-year model simulations showed favorability for GEA. For example, cumulative 2-year (discounted) costs for AUB patients treated with GEA were $\$ 25,979$ compared with $\$ 36,211$ for $\mathrm{OPH}$ and $\$ 42,402$ for IPH, thus showing respective incremental cost savings for GEA ranging from $\$ 10,232(-39.4 \%)$ to $\$ 16,423(-63.2 \%)$. Cumulative 3-year incremental cost savings for GEA vs. OPH and vs. IPH ranged from $\$ 8996(-26.1 \%)$ to $\$ 15,914$ $(-46.1 \%)$, respectively.

Total QALYs in the first year after intervention for commercial-payer AUB patients treated with GEA were 0.8304 , compared with 0.8143 for $\mathrm{OPH}$ and 0.8156 for IPH, thus showing an incremental gain for GEA ranging from 0.0162 QALYs $(1.9 \%)$ to 0.0149 QALYs $(1.8 \%)$. Secondand third-year postintervention QALYs were relatively lower $(4.5 \%-4.7 \%)$ for GEA vs. OPH or IPH, owing to the occurrence of GEA reinterventions and their detrimental impact on quality of life, as well as the higher long-term utility associated with hysterectomy. Cumulative (discounted) 2-year incremental QALYs for GEA vs. OPH and vs. IPH ranged from $-0.0229(-1.1 \%)$ to $-0.0241(-1.1 \%)$, respectively, while cumulative 3-year incremental QALYs for GEA vs. OPH and vs. IPH ranged from $-0.0581(-2.5 \%)$ to $-0.0594(-2.5 \%)$, respectively.

Medicaid payer perspective. As would be expected, total and incremental differences in health care costs in the first year after intervention were less in the Medicaid analysis:
$\$ 13,645$ for AUB patients treated with GEA, compared with $\$ 14,494$ for OPH and $\$ 17,112$ for IPH, thus showing an incremental cost savings for GEA ranging from $\$ 849$ $(-6.2 \%)$ to $\$ 3467(-25.4 \%)$ (Table 5 and Fig. 2). Other disaggregated 1-year comparisons for inpatient, outpatient, and pharmacy costs are presented in Table 5.

Comparatively higher than the commercial payer analyses results, second- and third-year postintervention costs for Medicaid patients ranged from about $\$ 10,000$ to $\$ 14,000$ across all 3 interventions, with GEA costs higher (4.9\%$20.5 \%$ ) than OPH costs and higher (13.8\%-20.0\%) than IPH costs. However, cumulative costs across 2-year model simulations still showed favorability for GEA, where costs for AUB patients treated with GEA were $\$ 24,484$ compared with $\$ 24,756$ for OPH and $\$ 26,296$ for IPH, thus showing respective incremental cost savings for GEA ranging from $\$ 272$ $(-1.1 \%)$ to $\$ 1813(-7.4 \%)$. Cumulative incremental costs were higher for GEA by the third year, ranging from $\$ 2470(+6.7 \%)$ compared with OPH to $\$ 907(+2.4 \%)$ compared with IPH.

Total QALYs in the first year after intervention for Medicaid-payer AUB patients treated with GEA were 0.8317 , compared with 0.8115 for $\mathrm{OPH}$ and 0.8108 for IPH, thus showing an incremental gain for GEA ranging from 0.0201 QALYs (2.4\%) to 0.0209 QALYs (2.5\%). Similar to the commercial payer analyses, second- and third-year postintervention QALYs were relatively lower $(4.4 \%-4.7 \%)$ for GEA vs. $\mathrm{OPH}$ or IPH. Cumulative (discounted) 2-year incremental QALYs for GEA vs. OPH and vs. IPH ranged from -0.0185 $(-1.1 \%)$ to $-0.0178(-1.1 \%)$, respectively, while cumulative 3 year incremental QALYs for GEA vs. OPH and vs. IPH ranged from $-0.0529(-2.2 \%)$ to $-0.0523(-2.2 \%)$, respectively.

\section{Budget impact analysis}

Commercial payer perspective. The commercial payer budget impact analysis focused on 362 AUB patients in a hypothetical million-member health plan who would receive GEA or hysterectomy intervention in any given year 
Table 5. Cost and Quality-Adjusted Life Year Outcomes (Medicaid Payer Perspective)

\begin{tabular}{|c|c|c|c|c|c|c|c|c|c|}
\hline & GEA & $\mathrm{OPH}$ & $I P H$ & $\begin{array}{c}\triangle \text { GEA } \\
\text { vs. OPH }\end{array}$ & $\begin{array}{l}\triangle \text { DEA } \\
\text { vs. IPH }\end{array}$ & $\begin{array}{l}\triangle O P H \\
v S I P H\end{array}$ & $\begin{array}{l}\% \triangle G E A \\
v s . O P H\end{array}$ & $\begin{array}{l}\% \triangle G E A \\
v s . I P H\end{array}$ & $\begin{array}{l}\% \triangle O P H \\
\text { vs IPH }\end{array}$ \\
\hline Year 1 Total Cost & $\$ 13,645$ & $\$ 14,494$ & $\$ 17,112$ & $-\$ 849$ & $-\$ 3467$ & $-\$ 2618$ & $-6.2 \%$ & $-25.4 \%$ & $-18.1 \%$ \\
\hline Initial intervention & $\$ 766$ & $\$ 1107$ & $\$ 2822$ & $-\$ 341$ & $-\$ 2056$ & $-\$ 1716$ & $-44.5 \%$ & $-268.5 \%$ & $-155.0 \%$ \\
\hline $\begin{array}{l}\text { All other health care } \\
\text { (including reintervention) }\end{array}$ & $\$ 12,879$ & $\$ 13,388$ & $\$ 14,290$ & $-\$ 508$ & $-\$ 1411$ & $-\$ 902$ & $-3.9 \%$ & $-11.0 \%$ & $-6.7 \%$ \\
\hline Inpatient admissions & $\$ 1343$ & $\$ 1305$ & $\$ 3241$ & $\$ 38$ & $-\$ 1898$ & $-\$ 1937$ & $2.8 \%$ & $-141.4 \%$ & $-148.4 \%$ \\
\hline Outpatient services & $\$ 7508$ & $\$ 8366$ & $\$ 7225$ & $-\$ 859$ & $\$ 283$ & $\$ 1142$ & $-11.4 \%$ & $3.8 \%$ & $13.6 \%$ \\
\hline Emergency room visits & $\$ 816$ & $\$ 1020$ & $\$ 959$ & $-\$ 205$ & $-\$ 143$ & $\$ 61$ & $-25.1 \%$ & $-17.6 \%$ & $6.0 \%$ \\
\hline Physician office visits & $\$ 416$ & $\$ 411$ & $\$ 456$ & $\$ 5$ & $-\$ 40$ & $-\$ 45$ & $1.2 \%$ & $-9.6 \%$ & $-10.9 \%$ \\
\hline Other outpatient services & $\$ 6276$ & $\$ 6935$ & $\$ 5810$ & $-\$ 659$ & $\$ 466$ & $\$ 1125$ & $-10.5 \%$ & $7.4 \%$ & $16.2 \%$ \\
\hline Outpatient prescriptions & $\$ 4029$ & $\$ 3717$ & $\$ 3824$ & $\$ 312$ & $\$ 205$ & $-\$ 107$ & $7.7 \%$ & $5.1 \%$ & $-2.9 \%$ \\
\hline Year 2 Total Cost & $\$ 11,573$ & $\$ 11,004$ & $\$ 9973$ & $\$ 569$ & $\$ 1600$ & $\$ 1031$ & $4.9 \%$ & $13.8 \%$ & $9.4 \%$ \\
\hline Year 3 Total Cost & $\$ 14,171$ & $\$ 11,270$ & $\$ 11,342$ & $\$ 2901$ & $\$ 2829$ & $-\$ 72$ & $20.5 \%$ & $20.0 \%$ & $-0.6 \%$ \\
\hline $\begin{array}{l}\text { Cumulative Total } \\
\text { Cost (Years 1-2) } \\
\text { (Discounted at 3\%) }\end{array}$ & $\$ 24,484$ & $\$ 24,756$ & $\$ 26,296$ & $-\$ 272$ & $-\$ 1813$ & $-\$ 1541$ & $-1.1 \%$ & $-7.4 \%$ & $-6.2 \%$ \\
\hline $\begin{array}{l}\text { Cumulative Total Cost } \\
\text { (Years 1-3) } \\
\text { (Discounted at 3\%) }\end{array}$ & $\$ 37,128$ & $\$ 34,658$ & $\$ 36,221$ & $\$ 2470$ & $\$ 907$ & $-\$ 1564$ & $6.7 \%$ & $2.4 \%$ & $-4.5 \%$ \\
\hline Year 1 QALYs & 0.8317 & 0.8115 & 0.8108 & 0.0201 & 0.0209 & 0.0007 & $2.4 \%$ & $2.5 \%$ & $0.1 \%$ \\
\hline Year 2 QALYs & 0.8408 & 0.8800 & 0.8800 & -0.0392 & -0.0392 & 0.0000 & & & $0.0 \%$ \\
\hline Year 3 QALYs & 0.8429 & 0.8800 & 0.8800 & -0.0371 & -0.0371 & 0.0000 & $-4.4 \%$ & $-4.4 \%$ & $0.0 \%$ \\
\hline $\begin{array}{l}\text { Cumulative QALYs } \\
\text { (Years 1-2) } \\
\text { (Discounted at 3\%)) }\end{array}$ & 1.6238 & 1.6423 & 1.6416 & -0.0185 & -0.0178 & 0.0007 & $-1.1 \%$ & $-1.1 \%$ & $0.0 \%$ \\
\hline $\begin{array}{l}\text { Cumulative QALYs } \\
\text { (Years 1-3) } \\
\text { (Discounted at 3\%)) }\end{array}$ & 2.3710 & 2.4239 & 2.4232 & -0.0529 & -0.0523 & 0.0007 & $-2.2 \%$ & $-2.2 \%$ & $0.0 \%$ \\
\hline
\end{tabular}

All costs are in 2017 US dollars.

GEA, global endometrial ablation; IPH, inpatient hysterectomy; OPH, outpatient hysterectomy; QALY, quality-adjusted life year.

(Table 6). Increasing utilization of GEA by $20 \%$ and correspondingly decreasing utilization of OPH and IPH by $15 \%$ and $5 \%$, respectively, resulted in total annual health plan cost savings of approximately $\$ 906,000$, or about $\$ 0.08$ savings PMPM basis and \$208.45 savings PTMPM.

Medicaid payer perspective. Using the same statistics and assumptions - and the same hypothetical change in utilization scenario - the Medicaid budget impact analysis focused on 507 AUB patients who would receive an AUB intervention in any given year in a typical-sized State Medicaid plan with 1.4 million members (Table 6). Total annual Medicaid plan cost savings was about $\$ 152,000$, or $\$ 0.01$ savings PMPM and \$25.06 savings PTMPM.

\section{Cost-effectiveness analysis}

Commercial payer perspective. Cost-effectiveness metrics from a 1-year analysis show GEA treatment as economically dominant (conferring greater benefit at lower cost) over $\mathrm{OPH}$ and IPH in all circumstances (Table 7). However, because cumulative 2- and 3-year QALYs for GEA were lower than those for $\mathrm{OPH}$ and IPH, despite GEA costs being comparatively lower, decremental costeffectiveness ratios resulted in those scenarios, meaning that GEA promotes cost savings but is less effective in terms of conferring QALYs. Decremental cost-effectiveness ratios are asymmetric with the more conventional ICURs, which are intended to calculate an amount of money spent for every QALY gained.
Interpreting the ICURs presented in Table 7, under the commercial payer perspective, GEA saved $\$ 154,759$ and $\$ 268,104$ per QALY lost in the 3-year scenario comparing against $\mathrm{OPH}$ and IPH, respectively. Interpretation of decremental cost-utility ratios is subjective, but by some accepted standards these ratios would imply that GEA is "cost-effective.",34

\section{Medicaid payer perspective}

Medicaid cost-effectiveness analysis results were similar to the commercial payer analyses with regard to the 1- and 2-year analyses (Table 7). GEA dominated OPH and IPH in the 1-year analysis and had decremental cost-effectiveness in the 2-year scenario, with ICURs ranging from $\$ 14,699$ to $\$ 101,787$ for GEA vs. OPH and GEA vs. IPH, respectively. Results were different for the 3-year Medicaid costeffectiveness analysis, where GEA was dominated by OPH and IPH, owing to the comparatively higher health care costs and lower QALYs attained by Medicaid patients cumulatively over a 3-year simulation.

\section{Sensitivity analysis}

Model results were not highly sensitive to targeted changes in the complication rate and reintervention rate parameter values - that is, the changes did not appreciably alter the incremental costs and QALYs, nor did they generally affect conclusions about the budget impact and cost-effectiveness of GEA. 
Commercial payer perspective

Number of health care plan members:

$\%$ women $30-55$ years:

... \% diagnosed or treated with AUB:

... \% treated with GEA or hysterectomy:

Analysis population size:

GEA, OPH, and IPH Utilization

GEA

$\mathrm{OPH}$

IPH

Total cost

Mean cost per treated member

Cost per-member per-month

Cost per-treated-member per-month

Medicaid Payer Perspective

Number of Medicaid plan members:

$\%$ women $30-55$ years:

... \% diagnosed or treated with AUB:

... \% treated with GEA or hysterectomy:

Analysis population size:

GEA, OPH, and IPH Utilization

GEA

$\mathrm{OPH}$

IPH

Total cost

Mean cost per treated member

Cost per-member per-month (PMPM)

Cost per-treated-member per-month (PTMPM)
$1,000,000$

$16.3 \%$

$20.0 \%$

$1.1 \%$

362

Current Scenario

$55.8 \%$

$25.7 \%$

$18.5 \%$

$100.0 \%$

Current Scenario

$\$ 8,717,530$

$\$ 24,080$

$\$ 0.73$

$\$ 2006.67$

$1,400,000$

$16.3 \%$

$20.0 \%$

$1.1 \%$

507

\section{Current Scenario}

$54.5 \%$

$28.6 \%$

$17.0 \%$

$100.0 \%$

Current Scenario

$\$ 7,336,637$

$\$ 14,475$

$\$ 0.44$

$\$ 1206.29$
Revised Scenario

$75.8 \%$

$10.7 \%$

$13.5 \%$

$100.0 \%$

Revised Scenario

$\$ 7,811,951$

$\$ 21,579$

$\$ 0.65$

$\$ 1798.22$

$\underline{\text { Revised Scenario }}$

$74.5 \%$

$13.6 \%$

$12.0 \%$

$100.0 \%$

$\underline{\text { Revised Scenario }}$

$\$ 7,184,214$

$\$ 14,175$

$\$ 0.43$

$\$ 1181.23$ \begin{tabular}{c} 
Absolute $\Delta$ \\
\hline $20.0 \%$ \\
$-15.0 \%$ \\
$-5.0 \%$
\end{tabular}

Absolute $\Delta$

$-\$ 905,580$

$-\$ 2501$

$-\$ 0.08$

$-\$ 208.45$

$\% \Delta$

$-\overline{10.4 \%}$

$-10.4 \%$

$-10.4 \%$

$-10.4 \%$

AUB, abnormal uterine bleeding; GEA, global endometrial ablation; IPH, inpatient hysterectomy; OPH, outpatient hysterectomy.

Table 7. Cost-Effectiveness Analysis Results

Commercial payer perspective

\begin{tabular}{llll}
\hline Analysis time frame & \multicolumn{1}{c}{ GEA vs. OPH } & \multicolumn{1}{c}{ GEA vs. IPH } & OPH vs IPH \\
\hline Year 1 ICUR & $-\$ 688,450$ & $-\$ 1,120,916$ & $\$ 4,245,696$ \\
& GEA Dominant & GEA Dominant & OPH Decremental CE \\
Years 1-2 ICUR & $\$ 447,117$ & $\$ 680,086$ & $\$ 4,897,030$ \\
& GEA Decremental CE & GEA Decremental CE & OPH Decremental CE \\
Years 1-3 ICUR & $\$ 154,759$ & $\$ 268,104$ & $\$ 5,636,021$ \\
& GEA Decremental $\boldsymbol{C E}$ & $\mathbf{G E A}$ Decremental CE & OPH Decremental CE
\end{tabular}

Medicaid payer perspective

\begin{tabular}{llll}
\hline Analysis time frame & GEA vs. OPH & GEA vs. IPH & OPH vs IPH \\
\hline Year 1 ICUR & $-\$ 42,196$ & $-\$ 166,282$ & $-\$ 3,614,455$ \\
& GEA Dominant & GEA Dominant & OPH Dominant \\
Years 1-2 ICUR & $\$ 14,699$ & $\$ 101,787$ & $-\$ 2,190,863$ \\
Years 1-3 ICUR & GEA Decremental CE & GEA Decremental CE & OPH Dominant \\
& $-\$ 46,662$ & $-\$ 17,349$ & $-\$ 2,290,315$ \\
& GEA Dominated & GEA Dominated & OPH Dominant
\end{tabular}

All costs are in 2017 US dollars.

CE, cost-effectiveness; GEA, global endometrial ablation; ICUR, incremental cost-utility ratio; IPH, inpatient hysterectomy; OPH, outpatient hysterectomy.

"Dominant": The intervention costs less and is at least as effective as the comparator.

"Dominated": The intervention costs more and is no more effective than the comparator.

"Decremental CE': The intervention costs less and is no more effective than the comparator. 
Adjusting GEA utilities by $+25 \%$ had a substantial impact on the cost-effectiveness results, with GEA dominating $\mathrm{OPH}$ and IPH in all commercial analyses scenarios and dominating $\mathrm{OPH}$ and IPH in the Medicaid 1- and 2-year scenarios and generating positive ICURs in the 3-year scenario (\$15,140/QALY and \$5534/QALY for GEA vs. OPH and GEA vs. IPH, respectively). Adjusting GEA utilities by $-25 \%$ had the effect of generating decremental costeffectiveness ratios for all commercial payer and Medicaid scenarios, except for the 3-year Medicaid scenario in which GEA remained dominated by $\mathrm{OPH}$ and IPH.

Substituting median cost values from the MarketScan database analyses generated slightly less favorable results for GEA in the commercial payer analyses, with PMPM cost savings in the budget impact analysis reduced from $\$ 0.08$ to $\$ 0.04$ and PTMPM cost savings reduced from $\$ 208.45$ to $\$ 121.22$, alongside GEA transforming into a dominated strategy in the 3-year commercial payer cost-effectiveness analysis. Substituting median cost values in the Medicaid model revealed much more stable results, with PMPM savings unchanged at $\$ 0.01$ and PTMPM savings only slightly increasing from $\$ 25.06$ to $\$ 25.30$. (Data not shown.)

\section{Discussion}

\section{Principal findings}

Estimates generated by the economic modeling analyses suggest a substantial cost superiority and favorable budget impact and cost-effectiveness implications for GEA compared with OPH and IPH in the 1-year analyses from both the commercial payer and Medicaid perspectives. Remarkably, total health care costs for patients in the first year after intervention with GEA are up to $\$ 17,000$ less than costs for patients who opt for hysterectomy. Intervention costs alone are as much as $\$ 7000$ less for GEA vs. OPH or IPH. Moreover, these 1-year analysis costs savings are entwined with better quality-of-life outcomes for GEA patients, which ultimately leads to the authors' calculated conclusion that GEA is the economically dominant strategy for AUB treatment in the 1-year analysis scenario-ie, the "win-win" situation where greater benefits are conferred at lower cost.

The authors note, however, that longer term analyses over 2- and 3-year horizons tempered the clinical-economic benefits of GEA, primarily because of the potential for GEA reinterventions that are associated with cost and quality-oflife implications avoided by the permanence of hysterectomy.

Although previous studies ${ }^{23,24}$ have demonstrated that GEA is cost-effective compared to hysterectomy, this study is the first to examine specific clinical-economic comparisons of GEA with hysterectomy in a head-to-head fashion in both inpatient and outpatient settings. In general, OPH is associated with lower costs than IPH. Results of this study substantiate that GEA is economically favorable compared to both $\mathrm{OPH}$ and IPH, suggesting that there may be an opportunity to reduce overall health care costs to private (commercial) and public (Medicaid) payers if more women with AUB elected to undergo GEA rather than hysterectomy when appropriate.

\section{Limitations}

Several limitations of this study bear mention. The model does not differentiate among the various types of hysterec- tomy performed (ie, abdominal hysterectomy, vaginal hysterectomy, laparoscopically assisted vaginal hysterectomy, laparoscopic supracervical hysterectomy, total laparoscopic hysterectomy) and does not distinguish between standard and robotic-assisted procedures. Also, the underlying data may not discern channeling bias that may exist for characteristics of patients who opt for GEA over certain types of hysterectomy, or which may indirectly guide patients toward IPH instead of OPH and vice versa.

It is important to note that, although GEA is successful for most women, it is not definitive therapy for all. Reintervention with secondary GEA or hysterectomy is required for some women, sometimes many years after the initial intervention. The analyses presented here appropriately account for GEA reintervention and its associated costs; however, this is done on a cohort basis that looks across the spectrum of all women with AUB. Applying knowledge about predictors for GEA reintervention (eg, patient age, dysmenorrhea history, past tubal ligation, uterine pathology [including fibroids, adenomyosis, thickened endometrium, polyps, retroversion, and other pathology], previous cesarean section, smoking, obesity $)^{35}$ is useful for clinicians to exclude higher risk subsets of women who would have poorer outcomes and higher costs, but this study did not stratify patients in this manner.

Finally, although targeted sensitivity analyses were conducted to test the robustness of GEA model parameter values and their impact on model results, formal probabilistic sensitivity analyses were not conducted as part of this evaluation.

\section{Conclusion}

The economic modeling analyses results suggest strong financial favorability for GEA vs. OPH or IPH from both the commercial and Medicaid perspectives. Broader adoption of the GEA treatment option would align with the current shift in the US health care system toward valuebased care. These results and their implications will help inform discussions among clinicians, health care payers, and self-insured employers as they seek cost-effective AUB treatments in the future.

\section{Author Disclosure Statement}

Mr. Miller, Dr. Bonafede, and Ms. Cai are employees of Truven Health Analytics, an IBM Company, which received funding from Hologic, Inc., to conduct this study. Mr. Pohlman and Ms. Troeger are employees of Hologic, Inc., which provided funding to conduct this study. Dr. CholkeriSingh received consultancy fees from Hologic, Inc., for her contributions to this study. This study was sponsored by Hologic Inc., Marlborough, MA.

\section{References}

1. Committee on Practice Bulletins-Gynecology. Practice bulletin no. 136: management of abnormal uterine bleeding associated with ovulatory dysfunction. Obstet Gynecol 2013; 122:176-185.

2. Committee on Practice Bulletins-Gynecology. Practice bulletin no. 128: diagnosis of abnormal uterine bleeding in reproductive-aged women. Obstet Gynecol 2012;120:197-206.

3. Fox KE. Management of heavy menstrual bleeding in general practice. Curr Med Res Opin 2012;28:1517-1525. 
4. Munro MG, Crichley HO, Fraser IS. FIGO classification for causes of abnormal uterine bleeding. Int J Gynaecol Obstet 2011;113:3-13.

5. National Institute for Health and Care Excellence (NICE). Heavy menstrual bleeding: assessment and management. Clinical Guideline 44, updated August 2016. https://www. nice.org.uk/guidance/CG44 Accessed September 13, 2017.

6. Apgar BS, Kaufman AH, George-Nwogu U, Kittendorf A. Treatment of menorrhagia. Am Fam Physician 2007;75: 1813-1819.

7. Osei J, Critchley H. Menorrhagia, mechanisms and targeted therapies. Curr Opin Obstet Gynecol 2005;17:411-418.

8. Oehler MK, Rees MC. Menorrhagia: an update. Acta Obstet Gynecol Scand 2003;82:405-422.

9. Sweet MG, Schmidt-Dalton TA, Weiss PM, Madsen KP. Evaluation and management of abnormal uterine bleeding in premenopausal women. Am Fam Physician 2012;85:35-43.

10. Centers for Disease Control and Prevention (CDC). Blood disorders in women: heavy menstrual bleeding. 2011. www.cdc.gov/ncbddd/blooddisorders/women/menorrhagia. html Accessed August 14, 2017.

11. Liu Z, Doan QV, Blumenthal P, Dubois RW. A systematic review evaluating health-related quality of life, work impairment, and health-care costs and utilization in abnormal uterine bleeding. Value Health 2007;10:183-194.

12. Spencer CP, Whitehead MI. Endometrial assessment revisited. Br J Obstet Gynaecol 1999;106:623-632.

13. Stovall DW. Alternatives to hysterectomy: focus on global endometrial ablation, uterine fibroid embolization, and magnetic resonance-guided focused ultrasound. Menopause 2011;18:437-444.

14. Canali C. Global endometrial ablation for menorrhagia: the office option. May 1, 2012. https://www.yumpu.com/en/ document/view/40996420/global-endometrial-ablation-obgynnews/3 Accessed September 13, 2017.

15. Lukes A, Evantash E. The issue of scarring post-ablation: the data. Contemp Ob Gyn 2012:57:33-36.

16. Campbell P, Monoghan C, Parker M. NovaSure endometrial ablation: a review of 400 cases. Gynecol Surg 2012;9: 73-76.

17. Clark TJ, Samuel N, Malick S, Middleton LJ, Daniels J, Gupta JK. Bipolar radiofrequency compared with thermal balloon endometrial ablation in the office: a randomized controlled trial. Obstet Gynecol 2011;117:109-118.

18. Cooper K, Lee A, Chien P, Raja E, Timmaraju V, Bhattacharya S. Outcomes following hysterectomy or endometrial ablation for heavy menstrual bleeding: retrospective analysis of hospital episode statistics in Scotland. BJOG 2011;118:1171-1179.

19. Penninx JP, Mol BW, Engels R, et al. Bipolar radiofrequency endometrial ablation compared with hydrothermablation for dysfunctional uterine bleeding: a randomized controlled trial. Obstet Gynecol 2010;116:819-826.

20. El-Nashar SA, Hopkins MR, Creedon DJ, et al. Prediction of treatment outcomes after global endometrial ablation. Obstet Gynecol. 2009;113:97-106. Erratum in: Obstet Gynecol 2010;115:663.

21. Kleijn JH, Engels R, Bourdrez P, Mol BW, Bongers MY. Five-year follow-up of a randomized controlled trial comparing NovaSure and ThermaChoice endometrial ablation. BJOG 2008;112:1214-1220.

22. Longinotti MK, Jacobson GF, Hung YY, Learman LA. Probability of hysterectomy after endometrial ablation. Obstet Gynecol 2008;112:1214-1220.
23. Miller JD, Lenhart GM, Bonafede MM, Basinski CM, Lukes AS, Troeger KA. Cost-effectiveness of endometrial ablation with the NovaSure ${ }^{\circledR}$ system versus other global ablation modalities and hysterectomy for treatment of abnormal uterine bleeding: US commercial and Medicaid payer perspectives. Int J Womens Health 2015;7:59-73.

24. Miller JD, Lenhart GM, Bonafede MM, Lukes AS, Laughlin-Tommaso SK. Cost-effectiveness of global endometrial ablation vs. hysterectomy for treatment of abnormal uterine bleeding: US commercial and Medicaid payer perspectives. Popul Health Manag 2015;18:373-382.

25. Spencer JC, Louie M, Moulder JK, et al. Cost-effectiveness of treatments for heavy menstrual bleeding. Am J Obstet Gynecol 2017;217:574e1-574.e9.

26. Bhattacharya S, Middleton LJ, Tsourapas A, et al. Hysterectomy, endometrial ablation and Mirena ${ }^{\circledR}$ for heavy menstrual bleeding: a systematic review of clinical effectiveness and cost-effectiveness analysis. Health Technol Assess 2011;15:iii-xvi, 1-252.

27. Roberts TE, Tsourapas A, Middleton LJ, et al. Hysterectomy, endometrial ablation, and levonorgestrel releasing intrauterine system (Mirena) for treatment of heavy menstrual bleeding: cost effectiveness analysis. BMJ 2011;342:d2202.

28. Dällenbach P, Kaelin-Gambirasio I, Dubuisson JB, Boulvain M. Risk factors for pelvic organ prolapse repair after hysterectomy. Obstet Gynecol 2007;110:625-632.

29. Clegg JP, Guest JF, Hurskainen R. Cost-utility of levonorgestrel intrauterine system compared with hysterectomy and second generation endometrial ablative techniques in managing patients with menorrhagia in the UK. Curr Med Res Opin 2007;23:1637-1648.

30. Garside R, Stein K, Wyatt K, Round A, Price A. The effectiveness and cost-effectiveness of microwave and thermal balloon endometrial ablation for heavy menstrual bleeding: a systematic review and economic modelling. Health Technol Assess 2004;8:iii, 1-155.

31. Sculpher M. A cost-utility analysis of abdominal hysterectomy versus transcervical endometrial resection for the surgical treatment of menorrhagia. Int $\mathbf{J}$ Technol Assess Health Care 1998;14:302-319.

32. Hurskainen R, Teperi J, Rissanen P, et al. Clinical outcomes and costs with the levonorgestrel-releasing intrauterine system or hysterectomy for treatment of menorrhagia: randomized trial 5-year follow-up. JAMA 2004;291:1456-1463.

33. Centers for Medicare \& Medicaid Services. Medicaid managed care enrollment and program characteristics 2014. https://www.medicaid.gov/medicaid-chip-programinformation/by-topics/data-and-systems/medicaid-managedcare/downloads/2014-medicaid-managed-care-enrollmentreport.pdf Accessed August 14, 2017.

34. Nelson AL, Cohen JT, Greenberg D, Kent DM. Much cheaper, almost as good: decrementally cost-effective medical innovation. Ann Intern Med 2009;151:662-667.

35. Cholkeri-Singh A. Predictors of endometrial ablation failure. Presented at: Global Congress on Hysteroscopy; Barcelona, Spain; May 2-5, 2017.

Address correspondence to: Jeffrey D. Miller, MS

Truven Health Analytics, an IBM Company 75 Binney Street Cambridge, MA 02142

E-mail: jffmill@us.ibm.com 